\title{
pesquisa
}

BACKES, F.A.A.L.; SANTOS, O.; SCHMIDT, D.; NOGUEIRA FILHO, H.; MANFRON, P.A.; CASAROLI, D. Reposição de nutrientes durante três cultivos de alface em hidroponia. Horticultura Brasileira, Brasília, v. 21, n. 4, p. 590-596, outubro-dezembro 2003.

\section{Reposição de nutrientes durante três cultivos de alface em hidroponia ${ }^{1}$}

\author{
Fernanda Alice A.L. Backes; Osmar Santos; Denise Schmidt; Hercules Nogueira Filho; Paulo Augusto \\ Manfron; Derblai Casaroli
}

UFSM, Depto. Fitotecnia, 97105-900 Santa Maria-RS; E-mail: osmar_santos@hotmail.br

\begin{abstract}
RESUMO
O experimento foi realizado em estufa plástica na UFSM, de agosto a novembro/99. Avaliou-se cinco formas de reposição de nutrientes na solução nutritiva com base na condutividade elétrica (CE), no sistema 'NFT' (Nutrient Film Technique) e duas cultivares de alface: Regina e Deisy, cultivadas em bancadas de sustentação formadas por telhas de fibro-cimento revestidas com tinta betuminosa Neutrol®. Foram dispostas 14 plantas por canal para cada repetição e uma cultivar em cada três canais, totalizando 84 plantas por bancada de produção. Comparou-se a eficiência de métodos de reposição de nutrientes na produção de alface, assim como a utilização da mesma solução, com reposição de nutrientes, durante três cultivos consecutivos. O delineamento experimental foi de blocos casualizados, com três repetições, em esquema fatorial $5 \times 2$. Os resultados demonstraram que o desempenho das cultivares avaliadas não foi influenciado pelos métodos de reposição de nutrientes. A ausência de reposição de nutrientes na solução nutritiva, durante um cultivo, permitiu maior produtividade da cultura, não se recomendando a reposição quando o objetivo for renovar a solução ao final do cultivo. As formas de reposição de nutrientes na solução nutritiva, durante o primeiro e segundo cultivos, não alteraram a produtividade da cultura em relação à renovação completa da solução nutritiva ao final do cultivo hidropônico. Para a reutilização de solução nutritiva, recomenda-se a reposição de nutrientes sempre que a CE diminuir $50 \%$ da inicial, possibilitando a produção por pelo menos três cultivos.
\end{abstract}

Palavras-chave: Lactuca sativa L., cultivo hidropônico, solução nutritiva, condutividade elétrica.

\begin{abstract}
Nutrient replacement during three cultivation seasons of lettuce in hydroponics

The experiment was carried out in a plastic greenhouse of the "Universidade Federal de Santa Maria", Brazil, from August to November 1999. In the 'NFT' (Nutrient Film Technique) five nutrient replacement manners in the nutrient solution were evaluted, based on the electrical conductivity (EC) and Regina and Deisy cultivars growing in production benches made by asbestos cement tiles. In each replication were put fourteen plants and one cultivar in each three channels totalling eighty-four plants in a production bench. We compared the efficiency of nutrient replacement methods on the growth of lettuce as well as the use of the same solution with nutrient replacement during three consecutive growing seasons. The experimental design was of randomized blocks with three replications in a $5 \times 2$ factorial scheme. The performance of the cultivars was not influenced by nutrient replacement methods. The absence of nutrient replacement in the solution during one growing season provided higher yield of lettuce. The replacement is not recommended when the objective is the renovation of the solution at the end of the growing season. The nutrient replacement forms, during the first and second growing seasons, did not alter the yield when compared to the complete renewal of the solution at the end of the growing season. To reutilize the same solution, it is advisable to replace nutrients whenever the EC decreases 50\% from the initial level.
\end{abstract}

Keywords: Lactuca sativa L., hydroponics, nutrient solution, electrical conductivity.

\section{(Recebido para publicação em 22 de abril de 2002 e aceito em 30 de abril de 2003)}

$\mathrm{O}$ cultivo hidropônico de plantas, na sua conceituação moderna, é bastante recente e faz parte de uma área maior do conhecimento denominada "cultivos sem solo". No Brasil, o cultivo hidropônico em escala comercial vem crescendo de forma rápida, destacandose os estados de São Paulo, Minas Gerais e Rio Grande do Sul que vêm desenvolvendo pesquisas pioneiras para a implantação da hidroponia (Santos, 2000a).

A alface é a espécie de maior expressão no sistema de cultivo sem solo, pos- sivelmente, por ser a hortaliça folhosa de maior consumo e importância no País, sendo que o principal sistema de produção é o 'NFT' (Nutrient Film Technique), onde a solução nutritiva constitui um dos aspectos mais importantes na obtenção de produtos vegetais de alta qualidade. A solução nutritiva é o meio pelo qual os nutrientes previamente dissolvidos na água são colocados à disposição das plantas e, é tida como uma das partes mais importantes de todo o sistema hidropônico, sendo que o mau uso desta pode acarretar sérios prejuízos para as plantas (Martinez \& Silva Filho, 1997; Andriolo, 1999). Furlani et al. (1999) salientam que muitos cultivos hidropônicos não obtêm sucesso, principalmente devido ao desconhecimento dos aspectos nutricionais desse sistema de produção o qual requer formulação e manejo adequados das soluções nutritivas. Segundo Hoagland \& Arnon (1950) diversas soluções têm sido usadas com sucesso pela pesquisa, mas nenhuma solução nutritiva é supe-

\footnotetext{
1 Parte da dissertação apresentada à UFSM para obtenção do grau de mestre em agronomia na área de produção vegetal
} 
rior a outras no que diz respeito a sua composição, pois as plantas têm acentuada capacidade de se adaptarem em diferentes condições nutritivas. Relatam, ainda, que um adequado fornecimento de nutrientes está diretamente relacionado com o volume de solução, estádio de desenvolvimento das plantas, taxa de absorção de nutrientes e freqüência de renovação e reposição de nutrientes na solução nutritiva.

A manutenção e renovação da solução nutritiva são aspectos importantes a serem considerados em hidroponia. Barbosa \& Martinez (1996) consideram que as plantas absorvem mais água que nutrientes, de modo que, se o volume consumido diariamente for reposto com a adição de mais solução, haverá crescente salinização do meio de cultivo, o que prejudicará o desenvolvimento radicular e a absorção de água. Dessa forma, o volume de solução consumido deve ser reposto com água. Ainda, com a absorção, ocorre diminuição dos nutrientes na solução nutritiva, até chegarse a uma situação em que a capacidade de nutrição da solução se esgota e, nesse ponto, a mesma deve ser renovada. Resh (1997) considera que a vida útil de uma solução nutritiva depende principalmente da porcentagem de acumulação de íons não utilizados pelas plantas de forma imediata. Esse acúmulo resulta em elevação da concentração osmótica da solução nutritiva. O autor ressalta ainda que não se deveria utilizar a solução nutritiva por um período superior a três meses, recomendando a renovação completa da mesma após este período. Já Castellane \& Araújo (1995) consideram que, em um sistema fechado, o período útil da solução nutritiva é de três a quatro semanas, enquanto que, para Santos (2000b), o período de utilização da solução está compreendido entre 60 e 90 dias.

Vários métodos de reposição de nutrientes são usados em hidroponia e, a adoção de uma forma de reposição de nutrientes na solução nutritiva é sempre discutível, pela carência de comprovação da eficiência dos diversos métodos em relação à produção e à resposta das plantas cultivadas em solução nutritiva sem reposição, no sistema de fluxo laminar de nutrientes. Um sistema automático de controle de nutrientes na solução nutritiva foi proposto por Nielsen (1984), com base no ajuste do nível de água, da concentração de nutrientes e do pH. Em um nível de água constante, a queda na concentração de nutrientes é altamente correlacionada com a diminuição da condutividade elétrica, a qual pode ser usada como monitor do nível de nutrientes na solução. Neste método, os níveis de nutrientes na solução recirculante podem ser mantidos pela adição de soluções de manutenção onde as proporções de nutrientes devem ser iguais ao influxo médio da cultura, o qual é igual à proporção de nutrientes na fitomassa seca e pode ser obtida através da análise química da planta. No cultivo de plantas em sistemas fechados, Jensen \& Collins (1985) propõem iniciar o cultivo com uma nova solução e, ao final de uma semana, adicionar $50 \%$ da formulação inicial, afim de manter um balanço adequado de nutrientes absorvidos pela planta. Ao final da segunda semana, a solução deverá ser totalmente substituída por uma nova e este procedimento deverá ser repetido até a cultura completar seu ciclo de produção. Em cultivos comerciais Martinez \& Silva Filho (1997) sugerem o uso da relação entre a concentração de nutrientes e a condutividade elétrica para a reposição dos sais na solução nutritiva, quando houver redução da condutividade elétrica a $35 \%$ do valor inicial. Furlani (1998) desenvolveu um sistema de ajuste químico de solução nutritiva para o cultivo de folhosas, através do monitoramento da condutividade elétrica, onde se procede a adição de nutrientes na solução nutritiva com soluções estoque sempre que houver queda de $0,25 \mathrm{mS} \mathrm{cm}^{-1}$ na condutividade elétrica inicial.

O presente trabalho tem como objetivos comparar a eficiência de métodos de reposição de nutrientes na solução nutritiva para a produção de duas cultivares de alface e, avaliar a utilização da mesma solução, com reposição de nutrientes, durante três cultivos consecutivos.

\section{MATERIAL E MÉTODOS}

O experimento foi conduzido em estufa plástica na Universidade Federal de Santa Maria, RS, de 02/08 a 29/11/ 99. Os dados meteorológicos de temperatura máxima e mínima $\left({ }^{\circ} \mathrm{C}\right)$, umidade relativa do ar máxima e mínima (\%) e radiação global (cal $\mathrm{cm}^{-2} \mathrm{dia}^{-1}$ ) registrados durante o período experimental foram de $27,7^{\circ} \mathrm{C}$ e $14^{\circ} \mathrm{C}, 94 \%$ e $50 \%, 376,4 \mathrm{Rg}\left(\mathrm{cal} \mathrm{cm}{ }^{-2} \mathrm{dia}^{-1}\right) ; 31^{\circ} \mathrm{C} \mathrm{e}$ $17,5^{\circ} \mathrm{C}, 93 \%$ e $49 \%, 374 \mathrm{Rg}\left(\mathrm{cal} \mathrm{cm}^{-2}\right.$ $\left.\mathrm{dia}^{-1}\right) ; 30,5^{\circ} \mathrm{C}$ e $17^{\circ} \mathrm{C}, 86,5 \%$ e $47,5 \%$, $385 \mathrm{Rg}\left(\mathrm{cal} \mathrm{cm}^{-2} \mathrm{dia}^{-1}\right)$ para o primeiro, segundo e terceiro cultivos, respectivamente.

Foram utilizadas cinco formas de reposição de nutrientes na solução nutritiva: Tratamento 1 (T1) (sem reposição de nutrientes e com renovação da solução ao final de cada cultivo); Tratamento 2 (T2) (reposição de nutrientes quando diminuiu $0,25 \mathrm{mS} \mathrm{cm}^{-1}$ na $\mathrm{CE}$ inicial e renovação da solução ao final de cada cultivo); Tratamento 3 (T3) (reposição de nutrientes quando diminuiu $0,25 \mathrm{mS} \mathrm{cm}^{-1}$ na CE inicial, durante três cultivos); Tratamento 4 (T4) (reposição de nutrientes quando diminuiu $50 \%$ da CE inicial e renovação da solução ao final de cada cultivo); Tratamento 5 (T5) (reposição de nutrientes quando diminuiu $50 \%$ da CE inicial, durante três cultivos). Foram usadas as cultivares de alface Regina (lisa) e Deisy (crespa).

Os tratamentos T2 e T3 seguiram o ajuste de solução nutritiva proposto por Furlani (1998). Para uma queda na CE inicial de $0,25 \mathrm{mS} \mathrm{cm}^{-1}$, utilizou-se a adição de sais através das soluções estoque $\mathrm{A}(1 \mathrm{~L} / 1000 \mathrm{~L}), \mathrm{B}(1 \mathrm{~L} / 1000 \mathrm{~L})$ e $\mathrm{M}$ (50 ml/1000L), cujas composições químicas são de $1.200 \mathrm{~g} \mathrm{KNO}_{3} / 10 \mathrm{~L} ; 200 \mathrm{~g}$ $\mathrm{NH}_{4} \mathrm{H}_{2} \mathrm{PO}_{4} / 10 \mathrm{~L}$ e $240 \mathrm{~g} \mathrm{MgSO} \mathrm{g}_{4} \cdot 7 \mathrm{H}_{2} \mathrm{O} /$ $10 \mathrm{~L} ; 600 \mathrm{~g} \mathrm{Ca}\left(\mathrm{NO}_{3}\right)_{2} \cdot 4 \mathrm{H}_{2} \mathrm{O} / 10 \mathrm{~L}$ e $300 \mathrm{~g}$ $\mathrm{NH}_{4} \mathrm{NO}_{3} / 10 \mathrm{~L} ; 10 \mathrm{~g} \mathrm{\textrm {MSO } _ { 4 }} \cdot 4 \mathrm{H}_{2} \mathrm{O} / \mathrm{L} ; 5 \mathrm{~g}$ $\mathrm{H}_{3} \mathrm{BO}_{3} / \mathrm{L} ; 2 \mathrm{~g} \mathrm{ZnSO}{ }_{4} .7 \mathrm{H}_{2} \mathrm{O} / \mathrm{L} ; 1 \mathrm{~g}$ $\mathrm{CuSO}_{4} .5 \mathrm{H}_{2} \mathrm{O} / \mathrm{L} ; 1 \mathrm{~g} \mathrm{Na}_{2} \mathrm{MoO}_{4} \cdot 2 \mathrm{H}_{2} \mathrm{O} / \mathrm{L} \mathrm{e}$ $200 \mathrm{ml}$ de Fe-EDTA, respectivamente. Os tratamentos T4 e T5 seguiram o método de reposição de nutrientes com base na adição de $50 \%$ da formulação inicial quando a $\mathrm{CE}$ inicial teve uma redução de $50 \%$. O delineamento experimental adotado foi o de blocos casualizados, com três repetições, em esquema fatorial $5 \times 2$, sendo cinco formas de reposição e duas cultivares.

A semeadura foi realizada em bandejas de isopor de 288 células, conten- 
Tabela 1. Fitomassa fresca e seca total (g.planta $\left.{ }^{-1}\right)$ e número de folhas de alface cultivada em hidroponia, considerando cinco formas de reposição de nutrientes na solução, no primeiro cultivo $\left(C_{1}\right)$, segundo cultivo $\left(C_{2}\right)$ e terceiro cultivo $\left(C_{3}\right)$. Santa Maria, UFSM. 1999.

\begin{tabular}{lccccccccc}
\hline \multirow{2}{*}{ Reposições $^{1}$} & \multicolumn{3}{c}{ Fitomassa fresca total $^{*}$} & \multicolumn{3}{c}{ Fitomassa seca total } & \multicolumn{3}{c}{ Número de folhas } \\
\cline { 2 - 11 } & $\mathbf{C}_{1}$ & $\mathbf{C}_{2}$ & $\mathbf{C}_{3}$ & $\mathbf{C}_{1}$ & $\mathbf{C}_{2}$ & $\mathbf{C}_{3}$ & $\mathbf{C}_{1}$ & $\mathbf{C}_{2}$ & $\mathbf{C}_{3}$ \\
\hline T1 & $309,1 \mathrm{a}$ & $342,4 \mathrm{a}$ & $392,7 \mathrm{~b}$ & $12,9 \mathrm{a}$ & $12,1 \mathrm{a}$ & $22,2 \mathrm{a}$ & $21,5 \mathrm{a}$ & $25,7 \mathrm{a}$ & $31,1 \mathrm{a}$ \\
T2 & $326,5 \mathrm{a}$ & $364,6 \mathrm{a}$ & $497,2 \mathrm{a}$ & $12,6 \mathrm{a}$ & $11,0 \mathrm{a}$ & $18,1 \mathrm{a}$ & $21,7 \mathrm{a}$ & $24,8 \mathrm{a}$ & $32,1 \mathrm{a}$ \\
T3 & $310,2 \mathrm{a}$ & $308,6 \mathrm{a}$ & $170,7 \mathrm{c}$ & $11,7 \mathrm{a}$ & $12,2 \mathrm{a}$ & $16,1 \mathrm{a}$ & $17,5 \mathrm{a}$ & $24,7 \mathrm{a}$ & $24,2 \mathrm{~b}$ \\
T4 & $292,5 \mathrm{a}$ & $388,9 \mathrm{a}$ & $557,6 \mathrm{a}$ & $12,3 \mathrm{a}$ & $13,4 \mathrm{a}$ & $20,8 \mathrm{a}$ & $21,2 \mathrm{a}$ & $25,6 \mathrm{a}$ & $31,0 \mathrm{a}$ \\
T5 & $336,0 \mathrm{a}$ & $366,0 \mathrm{a}$ & $506,0 \mathrm{a}$ & $12,4 \mathrm{a}$ & $12,1 \mathrm{a}$ & $20,2 \mathrm{a}$ & $21,8 \mathrm{a}$ & $26,1 \mathrm{a}$ & $36,1 \mathrm{a}$ \\
\hline Cultivares & \multicolumn{1}{c}{} & & & & & & & \\
\hline Regina & $267,0 \mathrm{~b}$ & $345,5 \mathrm{a}$ & $363,4 \mathrm{~b}$ & $9,7 \mathrm{~b}$ & $11,0 \mathrm{~b}$ & $16,1 \mathrm{~b}$ & $27,5 \mathrm{a}$ & $31,8 \mathrm{a}$ & $40,2 \mathrm{a}$ \\
Deisy & $362,7 \mathrm{a}$ & $362,8 \mathrm{a}$ & $486,4 \mathrm{a}$ & $15,1 \mathrm{a}$ & $13,4 \mathrm{a}$ & $22,9 \mathrm{a}$ & $15,8 \mathrm{~b}$ & $18,9 \mathrm{~b}$ & $21,6 \mathrm{~b}$ \\
\hline CV(\%) & 13,9 & 14,4 & 13,8 & 15,2 & 19,5 & 18,2 & 27,0 & 10,5 & 9,7 \\
\hline
\end{tabular}

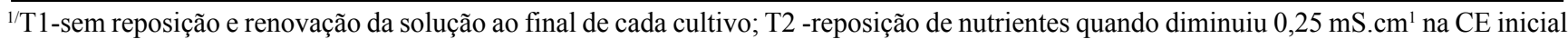
e renovação da solução ao final de cada cultivo; T3 -reposição de nutrientes quando diminuiu $0,25 \mathrm{mS} \mathrm{cm}^{-1}$ na $\mathrm{CE}$ inicial, durante três cultivos; T4 -reposição de nutrientes quando diminuiu 50\% da CE inicial e renovação da solução ao final de cada cultivo; T5 -reposição de nutrientes quando diminuiu $50 \%$ da CE inicial, durante três cultivos.

* Médias seguidas de pelo menos uma mesma letra não diferem entre si, pelo teste de Tukey ao nível de 5\% de probabilidade.

do substrato comercial Plantmax $\AA^{\circledR}$ e colocadas em piscina, com lâmina de solução nutritiva com $5,0 \mathrm{~cm}$ de profundidade. Nessa fase a solução nutritiva utilizada foi a recomendada por Castellane \& Araújo (1995), cuja composição química dos macronutrientes é 950; 900; 272; 246g/1000L de $\mathrm{Ca}\left(\mathrm{NO}_{3}\right)_{2} \cdot 4 \mathrm{H}_{2} \mathrm{O} ; \mathrm{KNO}_{3} ; \mathrm{KH}_{2} \mathrm{PO}_{4}$; $\mathrm{MgSO}_{4} .7 \mathrm{H}_{2} \mathrm{O}$, respectivamente; e, dos micronutrientes é 1,$70 ; 1,15 ; 0,19 ; 2,85$; $0,12 \mathrm{~g} / 1000 \mathrm{~L}$ de $\mathrm{MnSO}_{4} \cdot 4 \mathrm{H}_{2} \mathrm{O}$; $\mathrm{ZnSO}_{4} \cdot 7 \mathrm{H}_{2} \mathrm{O} ; \mathrm{CuSO}_{4} .5 \mathrm{H}_{2} \mathrm{O} ; \mathrm{Na}_{2} \mathrm{~B}_{4} \mathrm{O}_{7}$; $\mathrm{Na}_{2} \mathrm{MoO}_{4} \cdot 2 \mathrm{H}_{2} \mathrm{O}$ e $1000 \mathrm{ml}$ de Fe-EDTA, respectivamente, diluída a $25 \%$ da formulação inicial. $\mathrm{O}$ transplante para $\mathrm{o}$ berçário ocorreu quando as mudas apresentaram 4 a 5 folhas definitivas (aos 28; 24 e 24 dias no primeiro, segundo e terceiro cultivos, respectivamente). A solução nutritiva do berçário foi a mesma utilizada na piscina, porém, diluída a $50 \%$ da formulação inicial e, quando as plantas apresentavam aproximadamente 8 folhas definitivas (aos 39; $34 \mathrm{e}$ 37 dias, no primeiro, segundo e terceiro cultivos, respectivamente) foram transplantadas para as bancadas de produção final.

$\mathrm{Na}$ fase de produção final as plantas foram cultivadas em telhas de fibro-cimento impermeabilizadas com tinta betuminosa $\mathrm{Neutrol}^{\circledR}$ e o espaçamento utilizado foi de $25 \mathrm{~cm}$ entre plantas na linha e $22 \mathrm{~cm}$ entre plantas de linhas distintas. Foram dispostas 14 plantas por canal para cada repetição e uma cultivar em cada três canais, totalizando 84 plantas por bancada de produção. A solução nutritiva utilizada nesta fase foi a recomendada por Castellane \& Araújo (1995) a $100 \%$ da formulação inicial, para todos os tratamentos. $\mathrm{O} \mathrm{pH}$ da solução foi monitorado diariamente, após completar o volume do reservatório com

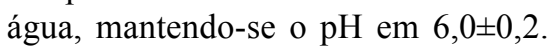
Posteriormente à leitura do $\mathrm{pH}$ efetuava-se a leitura da $\mathrm{CE}$ inicial, sendo esta considerada para a realização da reposição de nutrientes.

A colheita, nos três cultivos, foi realizada após 25 dias de permanência das plantas nas bancadas definitivas, totalizando 64 dias no primeiro cultivo, 59 dias no segundo e 62 dias no terceiro, da semeadura à colheita. As características avaliadas foram fitomassa fresca e seca total e número de folhas. Foram realizadas análises químicas das soluções nutritivas em relação aos macronutrientes, após o término de cada cultivo. Os dados foram submetidos à análise de variância, sendo as médias comparadas entre si pelo teste de Tukey a $5 \%$ de probabilidade.

\section{RESULTADOS E DISCUSSÃO}

No primeiro cultivo não houve efeito significativo da interação entre repo- sição de nutrientes e cultivares. Do mesmo modo, não foram observadas diferenças significativas entre as cinco formas de reposição, quanto aos caracteres fitomassa fresca e seca total e número de folhas por planta (Tabela 1).

$\mathrm{O}$ tratamento $\mathrm{T} 1$, sem reposição de nutrientes, apresentou valores semelhantes aos encontrados nos tratamentos T2; T3; T4 e T5, com reposição de nutrientes ao longo do cultivo. Tal fato indica que, apesar da redução contínua da CE (Figura 1a), a solução Castellane \& Araújo (1995), em T1, apenas com reposição de água, foi suficiente para que as plantas completassem seu ciclo com bons resultados de produtividade. As reposições de nutrientes realizadas nas soluções (Figura 1a) mostraram que os tratamentos $\mathrm{T} 2$ e $\mathrm{T} 3$ receberam mais reposições, devido aos valores da CE atingirem mais rapidamente $\mathrm{o}$ limite de $0,25 \mathrm{mS} \mathrm{cm}^{-1}$ para o ajuste químico. As reposições foram realizadas ao longo do cultivo, variando a sua freqüência de acordo com o tratamento (Figura 1a). Nos tratamentos T4 e T5, as reposições foram em número menor e efetuadas mais próximas ao final do ciclo. Nestes tratamentos, a redução da CE inicial foi mais lenta, demorando mais tempo para atingir o limite de $50 \%$ para a reposição de nutrientes (Figura 1a).

A concentração de sais da solução nutritiva nos tratamentos $\mathrm{T} 2$ e $\mathrm{T} 3$ redu- 

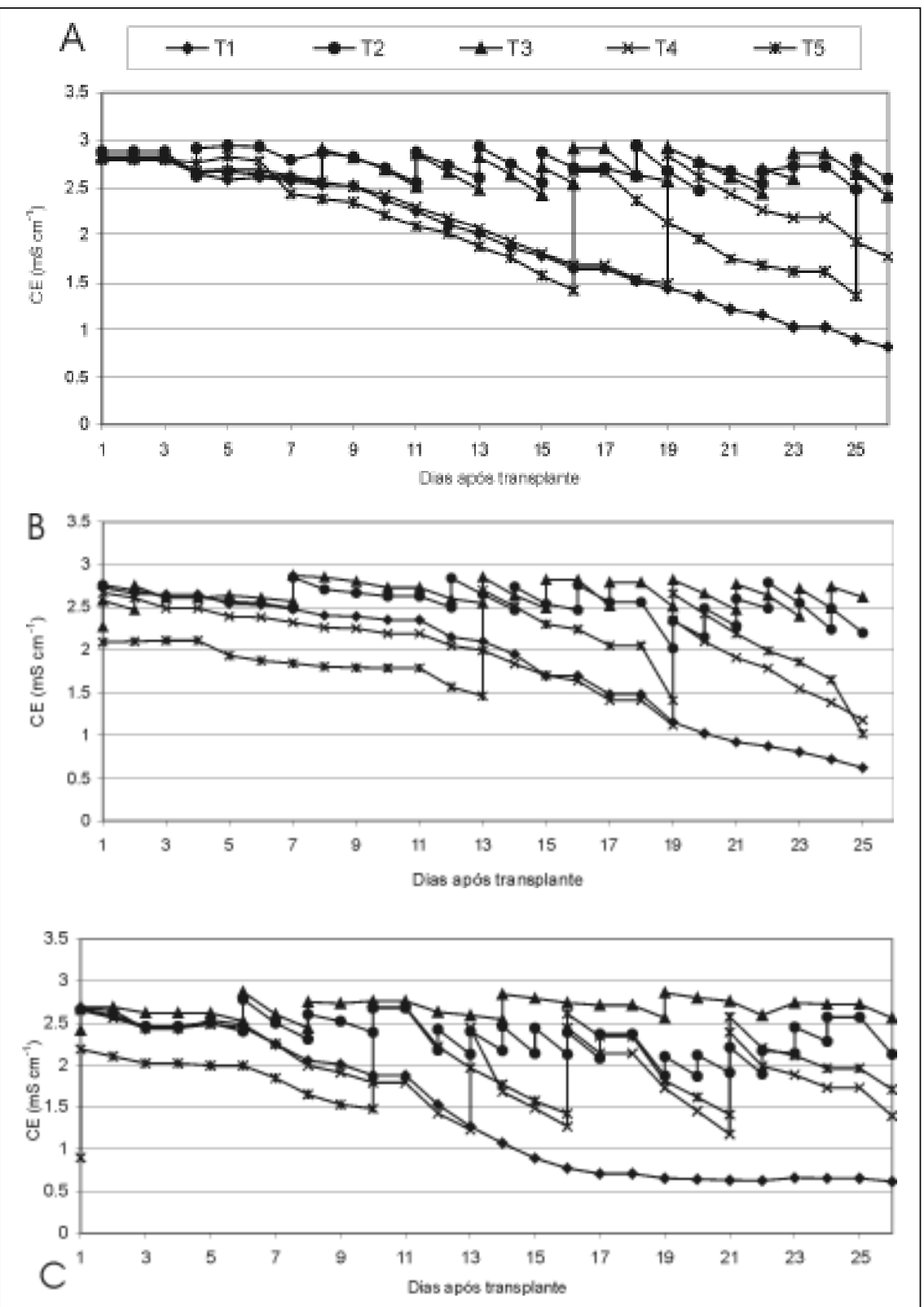

Figura 1. Valor diário da condutividade elétrica (CE) da solução nutritiva considerando cinco formas de reposição de nutrientes no primeiro cultivo (a), segundo cultivo (b) e terceiro cultivo (c) de alface. Santa Maria, UFSM. 1999.

ziu o $\mathrm{pH}$, provavelmente pela adição mais freqüente das soluções estoque. Além disso, pode ter ocorrido desbalanço na absorção de cátions e ânions (Figura 2a). Conforme Marschner (1995) a excessiva absorção de cátions, em relação aos ânions, pode acidificar a solução nutritiva.

As formas de reposição de nutrientes na solução não aumentaram a produtividade da alface em relação à renovação completa da solução nutritiva ao final do primeiro cultivo. Ademais, a renovação completa das soluções repre- se que, nos tratamentos T2; T3; T4 e T5, somente o magnésio apresentou valores dentro dos limites máximos referidos por Barry citado por Furlani et al. (1999) que são de $80 \mathrm{mg} \mathrm{L}^{-1}$ de fósforo; 400 $\mathrm{mg} \mathrm{L}^{-1}$ de potássio; $200 \mathrm{mg} \mathrm{L}^{-1}$ de cálcio e $80 \mathrm{mg} \mathrm{L}^{-1}$ de magnésio, sendo que para os demais nutrientes, os teores foram superiores a esses limites. Isso indica que as reposições dentro desses cultivos contribuíram para uma excessiva concentração de fósforo, potássio e cálcio na solução nutritiva. Apesar da maior concentração desses nutrientes na solução nutritiva, após o cultivo (Tabela 2b), não foi observado sintoma de fitotoxicidade nas plantas.

No segundo cultivo, assim como no primeiro, não houve interação entre formas de reposição e cultivares. Também não foram observadas diferenças significativas entre as formas de reposição em nenhuma das características avaliadas. Assim, as soluções nutritivas onde houve reposição de nutrientes por dois cultivos (tratamentos T3 e T5) mantiveram níveis de produção equivalentes ao tratamento T1 (renovação completa da solução), conforme Tabela 1. No método de ajuste químico com redução de $0,25 \mathrm{mS} \mathrm{cm}^{-1}$ na CE, Furlani (1998) recomenda a renovação de solução nutritiva mensalmente. Ainda, na realização de dois cultivos pode-se adotar a reposição de nutrientes ao invés de renovar a solução a cada cultivo, especialmente pelo método da redução de $50 \%$ na $\mathrm{CE}$ inicial, principalmente pelo menor número de reposições realizadas na solução nutritiva.

$\mathrm{O}$ número de reposições realizado nos tratamentos T2 e T3, no segundo cultivo, foi maior comparativamente ao cultivo anterior, mas nos tratamentos T4 e T5, o número de reposições foi igual nos dois cultivos. As reposições variaram de acordo com os tratamentos sendo que nos tratamentos T2 e T3, principalmente no final do cultivo, foram praticamente diárias (Figura 1b).

No segundo cultivo, o valor de $\mathrm{pH}$ foi semelhante ao do primeiro cultivo. Nos tratamentos T2 e T3, em que houve reposição, percebeu-se uma tendência para acidificação da solução nutritiva em função das soluções estoque apresentarem $\mathrm{pH}$ ácido. Para os tratamentos 
Tabela 2. Total de macronutrientes $\left(\mathrm{mg} \mathrm{L}^{-1}\right)$ na solução nutritiva durante os três cultivos consecutivos (a) e composição química da solução ( $\left.\mathrm{mg} \mathrm{L}^{-1}\right)$ ao final dos três cultivos de alface (b) em hidroponia. Santa Maria, UFSM. 1999.

\begin{tabular}{|c|c|c|c|c|c|c|c|c|c|c|c|c|}
\hline \multirow{3}{*}{$\begin{array}{l}\text { Repo- } \\
\text { sição }\end{array}$} & \multicolumn{3}{|c|}{ Fósforo (P) } & \multicolumn{3}{|c|}{ Potássio(K) } & \multicolumn{3}{|c|}{ Cálcio(Ca) } & \multicolumn{3}{|c|}{ Magnésio(Mg) } \\
\hline & \multicolumn{12}{|c|}{ Cultivos } \\
\hline & $1^{0}$ & $2^{\circ}$ & $3^{\circ}$ & $1^{0}$ & $2^{\circ}$ & $3^{\circ}$ & $1^{\circ}$ & $2^{\circ}$ & $3^{0}$ & $1^{\circ}$ & $2^{\circ}$ & $3^{\circ}$ \\
\hline \multicolumn{13}{|l|}{$\overline{(a)}$} \\
\hline$\overline{\mathrm{T} 1}$ & 62,6 & 62,6 & 62,6 & 402,9 & 402,9 & 402,9 & 161,5 & 161,5 & 161,5 & 24,6 & 24,6 & 24,6 \\
\hline $\mathrm{T} 2$ & 96,2 & 100,4 & 125,6 & 748,5 & 791,7 & 1050,9 & 243,1 & 253,3 & 314,5 & 43,8 & 46,2 & 60,6 \\
\hline T3 & 96,2 & 104,6 & 83,6 & 748,5 & 834,7 & 618,9 & 243,1 & 263,5 & 212,5 & 43,8 & 48,6 & 36,6 \\
\hline $\mathrm{T} 4$ & 93,8 & 93,8 & 156,4 & 604,3 & 604,3 & 1007,2 & 242,3 & 242,3 & 403,8 & 36,9 & 36,9 & 61,5 \\
\hline $\mathrm{T} 5$ & 125,1 & 125,1 & 156,4 & 805,8 & 805,8 & 1007,2 & 323,0 & 323,0 & 403,8 & 49,2 & 49,2 & 61,5 \\
\hline \multicolumn{13}{|l|}{ (b) } \\
\hline$\overline{\mathrm{T} 1}$ & 12,6 & 4,4 & 1,1 & 0,0 & 2,2 & 2,2 & 10,3 & 96,7 & 93,2 & 7,7 & 6,6 & 3,3 \\
\hline $\mathrm{T} 2$ & 27,5 & 15,4 & 1,6 & 171,6 & 114,4 & 121,0 & 16,9 & 218,6 & 205,5 & 14,5 & 36,4 & 36,7 \\
\hline T3 & 22,5 & 1,1 & 1,1 & 154,0 & 103,4 & 61,6 & 17,1 & 240,3 & 216,1 & 15,0 & 46,9 & 38,4 \\
\hline $\mathrm{T} 4$ & 34,1 & 20,3 & 10,7 & 70,4 & $<1$ & $<1$ & 17,9 & 181,4 & 198,1 & 14,0 & 23,4 & 31,1 \\
\hline $\mathrm{T} 5$ & 41,5 & 4,4 & 6,0 & 143,0 & $<1$ & $<1$ & 10,7 & 144,4 & 263,0 & 9,4 & 21,2 & 37,9 \\
\hline
\end{tabular}

${ }^{1 /}$ T1-sem reposição e com renovação da solução ao final de cada cultivo; T2 -reposição de nutrientes quando diminuiu $0,25 \mathrm{mS} \mathrm{cm}^{-1}$ na $\mathrm{CE}$ inicial e renovação da solução ao final de cada cultivo; T3 -reposição de nutrientes quando diminuiu $0,25 \mathrm{mS} \mathrm{cm}^{-1}$ na $\mathrm{CE}$ inicial, durante três cultivos; T4 -reposição de nutrientes quando diminuiu 50\% da CE inicial e renovação da solução ao final de cada cultivo; T5 -reposição de nutrientes quando diminuiu $50 \%$ da CE inicial, durante três cultivos.

T4 e T5, em geral, o pH manteve-se mais elevado, porém quando foram realizadas as reposições ocorreu redução do $\mathrm{pH}$, indicando que a adição dos sais tende a acidificar o meio pela maior concentração de nutrientes presentes na solução nutritiva. Nota-se que a reposição diária de água cujo $\mathrm{pH}$ era 6,4 contribuiu para a elevação dos níveis de $\mathrm{pH}$ na solução, principalmente em T1; T4 e T5 (Figura 2b).

Embora a cultivar Deisy tenha demonstrado melhor desempenho que a Regina, em relação a fitomassa seca total, quanto a massa fresca total, as cultivares não diferiram significativamente entre si. Para número de folhas, Regina (lisa) foi superior a Deisy (crespa), concordando com os resultados apresentados por Schmidt \& Santos (2000), que observaram um comportamento padrão, em que as cultivares do tipo lisa produzem maior número de folhas comparativamente as do tipo crespa. Bonnecarrère et al. (2000a) avaliaram o desempenho de cultivares de alface em hidroponia, no inverno, e observaram que, de maneira geral, as cultivares do tipo lisa apresentaram maior número de folhas que as cultivares do tipo crespa. Da mesma forma, Pilau et al. (2000), em cultivo na primavera, e Bonnecarrère et al. (2000b), no outono, observaram que a cultivar Regina foi superior à Deisy em número de folhas.

Analisando-se o total de macronutrientes na solução, durante o segundo cultivo (Tabela 2a), constatase que, para fósforo, potássio e cálcio, nos tratamentos T2; T3; T4 e T5, os teores estão acima dos relatados por Barry citado por Furlani et al. (1999). Isso pode ser explicado pelo número de reposições realizadas nestes tratamentos, enquanto que a testemunha (tratamento T1) apresentou níveis próximos aos limites máximos, apesar de não ter recebido adição de nutrientes. Não foram observados sintomas de fitotoxicidade nas plantas, apesar da alta concentração final de nutrientes nos tratamentos com reposição (Tabela $2 b$ ), principalmente em T2 e T3.

No terceiro cultivo não houve interação entre reposição e cultivares, porém observa-se que houve diferença significativa entre as formas de reposição para os caracteres fitomassa fresca total e número de folhas (Tabela 1). Verificou-se que, os tratamentos T2; T4 e T5 (com reposição) produziram significativamente mais fitomassa fresca comparativamente à testemunha (T1) e ao tratamento T3 (com reposição). Comparando-se os valores de fitomassa fresca total nos tratamentos T2; T4 e T5, neste cultivo, com os valores do segundo cultivo, observou-se que houve aumento de $26,6 \% ; 31,0 \%$ e $27,6 \%$, respectivamente, em função da adição de nutrientes, aliada às condições meteorológicas da época de cultivo, cujas médias das temperaturas máxima e mínima eram de $30,5^{\circ} \mathrm{C}$ e $17^{\circ} \mathrm{C}$, respectivamente, a umidade relativa do ar máxima de $86,5 \%$ e mínima de $47,5 \%$ e a radiação solar de $385 \mathrm{Rg}\left(\mathrm{cal} \mathrm{cm}^{-2}\right.$ dia $\left.^{-1}\right)$ favorecendo maior desenvolvimento das plantas.

$\mathrm{O}$ tratamento $\mathrm{T} 3$ não favoreceu $\mathrm{o}$ desenvolvimento normal das plantas neste cultivo, pois neste tratamento verificou-se menor crescimento da planta, como pode ser verificado para a massa fresca total e para número de folhas (Tabela 1). Por ocasião da colheita, as folhas tinham coloração verde intenso e acúmulo de látex, e as raízes estavam curtas e grossas e de coloração escura, depreciando a qualidade do produto. $\mathrm{O}$ excessivo número de reposições em $\mathrm{T} 3$ (23 reposições durante três cultivos) manteve os valores da CE elevados, afe- 


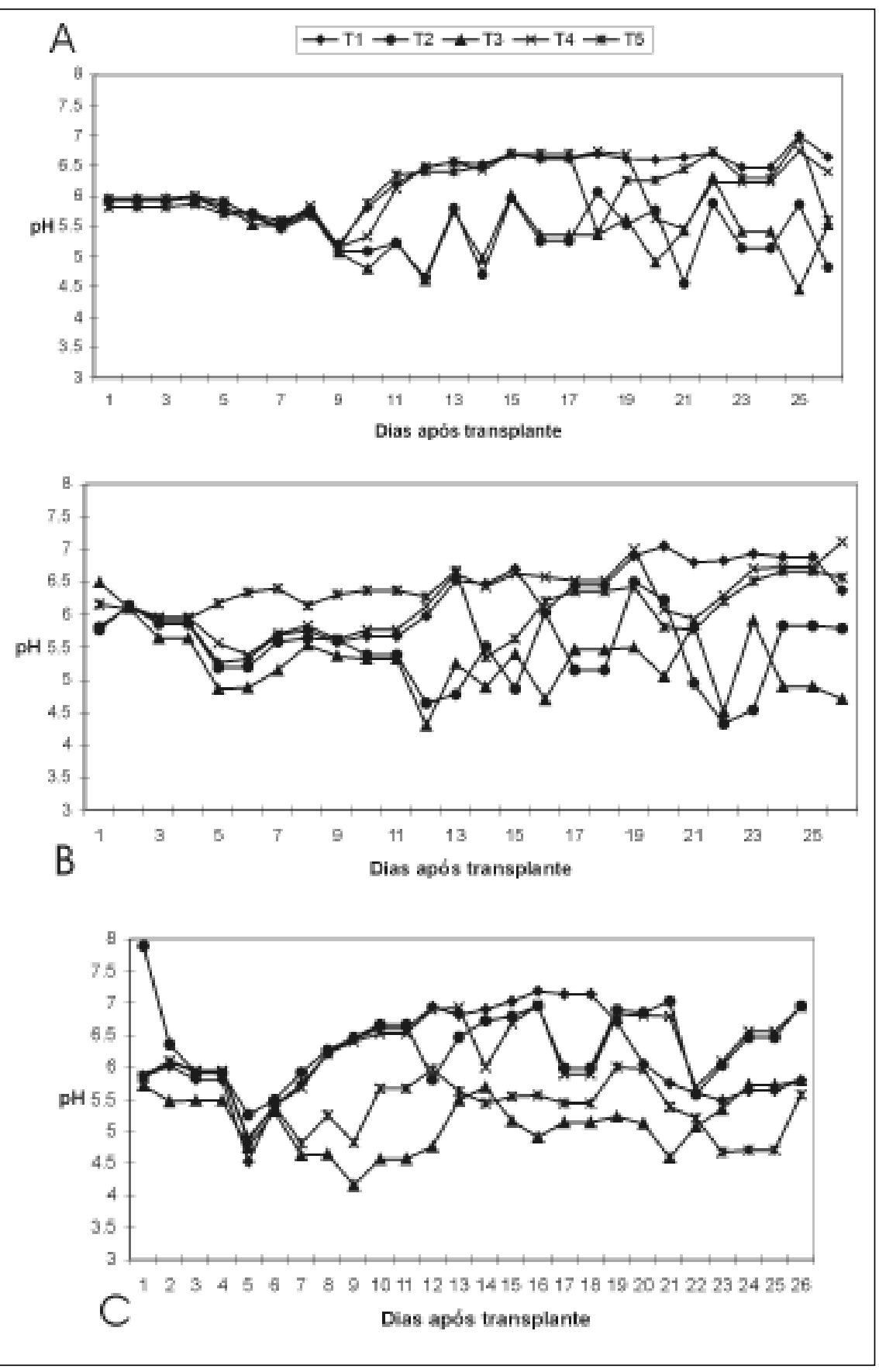

Figura 2. Valor diário do pH da solução nutritiva considerando cinco formas de reposição de nutrientes no primeiro cultivo (a), segundo cultivo (b) e terceiro cultivo (c) de alface. Santa Maria, UFSM. 1999.

tando a produtividade da cultura (Figura 1c). No entanto, para esta forma de reposição (redução de $0,25 \mathrm{mS} \mathrm{cm}^{-1}$ na CE inicial), verificou-se bom desempenho da solução nutritiva por dois cultivos, sem a renovação da solução, enquanto que Furlani (1998) recomenda a renovação mensal da solução para o mesmo ajuste químico. Abou-Hadid et al. (1996), cultivando alface em veram-se dentro da faixa ideal $(6,0 \pm 0,2)$ garantindo maior disponibilidade dos nutrientes na solução nutritiva.

$\mathrm{O}$ acúmulo de fitomassa seca total não diferiu entre os tratamentos (Tabela 1). Nos tratamentos T2; T3; T4 e T5 as soluções eram mais concentradas e o consumo de nutrientes foi maior. Segundo Schmidt (1999) as plantas cultivadas em condições de elevada concentração de nutrientes absorvem mais água, porém, no momento da secagem em estufa, estas perdem mais água, o que pode justificar a inexistência de diferenças significativas entre as formas de reposição, para a característica fitomassa seca total.

A cultivar Deisy foi superior à Regina em produção de fitomassa fresca e seca total por apresentar folhas de maior tamanho, considerando que a cultivar Regina foi superior àquela em número de folhas (Tabela 1). Esses resultados são semelhantes aos obtidos por Schmidt et al. (2000) com as mesmas cultivares em hidroponia.

Constata-se que o total de nutrientes adicionados à solução para atender as necessidades de fósforo, potássio e cálcio (tratamentos T2; T3; T4 e T5), conforme Tabela $2 \mathrm{a}$, estão acima do limite máximo referido por Barry na citação de Furlani et al. (1999). Após o cultivo, apesar dos nutrientes estarem acumulados na solução (Tabela 2 b), não foram observados sintomas de fitotoxicidade nas plantas, exceto no tratamento T3.

Conclui-se que, o desempenho das cultivares avaliadas não foi influenciado pelos métodos de reposição de nutrientes. A ausência de reposição de nutrientes na solução nutritiva, durante um cultivo, permitiu maior produtividade da cultura, não se recomendando a reposição quando o objetivo for renovar a solução ao final do cultivo. As formas de reposição de nutrientes na solução nutritiva, durante o primeiro e segundo cultivos, não alteraram a produtividade da cultura em relação à renovação completa da solução nutritiva ao final do cultivo hidropônico. Para a reutilização de solução nutritiva, recomenda-se a reposição de nutrientes sempre que a $\mathrm{CE}$ diminuir $50 \%$ da inicial, possibilitando a produção por pelo menos três cultivos. 


\section{LITERATURA CITADA}

ABOU-HADID, A.F.; ABD-ELMONIEM, E.M.; EL-SHINAWY, M.Z.; ABOU-ELSOUD, M. Electrical conductivity effect on growth and mineral composition of lettuce plants in hydroponic system. Acta Horticulturae, v. 434, p. 59-66, 1996. ANDRIOLO, J.L. Fisiologia das culturas protegidas. Santa Maria: UFSM, 1999. 142 p. BARBOSA, J.G.; MARTINEZ, H.E.P. O cultivo hidropônico do crisântemo. Viçosa: UFV, 1996, 9 p BONNECARRÈRE, R.A.G.; LONDERO, F.A.A.; SANTOS, O.S.; SCHMIDT, D. Desempenho de cultivares de alface em hidroponia, no inverno. Horticultura Brasileira, Brasília, v. 18, p. 283-284 2000, suplemento.

BONNECARRĖRE, R.A.G.; SCHMIDT, D.; CASAROLI, D.; SANTOS, O.S. Desempenho de cultivares de alface em hidroponia, no outono. Horticultura Brasileira, Brasília, v. 18, p. 289-291, 2000, suplemento.

CASTELLANE, P.D.; ARAÚJO, J.A.C. Cultivo sem solo-hidroponia. Jaboticabal: FUNEP, 1995, $43 \mathrm{p}$.
FURLANI, P.R. Instruções para o cultivo de hortaliças de folhas pela técnica de hidroponia - NFT. Campinas: Instituto Agronômico, 1998. 30 p. (Documentos IAC; 168).

FURLANI, P.R.; BOLONHEZI, D.; SILVEIRA, L.C.P.; FAQUIN, V. Nutrição mineral de hortaliças, preparo e manejo de soluções nutritivas. Informe Agropecuário, Belo Horizonte, v. 20, n. 200/ 201, p. 90-98, 1999

HOAGLAND, D.R.; ARNON, D.L. The water culture methods for growing plants without soil. Berkeley: University of California, 1950. 32 p. (Circular 347).

JENSEN, M.H.; COLLINS, W.L. Hydroponic vegetable production. Horticulturae Reviews, Arizona, v. 7, p. 483-558, 1985.

MARSCHNER, H. Mineral nutrition of higher plants. 2. ed. London: Academic Press, 1995. 889 p. MARTINEZ, H.E.P.; SILVA FILHO, J.B. Introdução ao cultivo hidropônico de plantas. Viçosa: UFV, 1997. 52 p.

NIELSEN, N.E. Crop production in recirculating nutrient solution according to the principle of regeneration. In: International Congress on Soilless Culture, 6th, Lunteren, The Netherlands. Proceedings... Lunteren: International Society for Soilless Culture, 1984. p. 421-446.
PILAU, F.G.; SCHMIDT, D.; NOGUEIRA, H.; SANTOS, O.S. Desempenho de cultivares de alface em hidroponia, na primavera. Horticultura Brasileira, v. 18, p. 284-286, 2000, suplemento.

RESH, H.M. Cultivos hidroponicos: nuevas técnicas de producción. 4 ed. Madrid: Ediciones Mundi-Prensa, 1997. 509 p.

SANTOS, O.S. Conceito, histórico e vantagens da hidroponia. In: SANTOS, O. Hidroponia da Alface. Santa Maria: UFSM, 2000a. p. 5-9.

SANTOS, O.S. Soluções nutritivas para alface. In: SANTOS, O. Hidroponia da Alface. Santa Maria: UFSM, 2000b. p. 90-101.

SCHMIDT, D. Soluções nutritivas, cultivares e formas de sustentação de alface cultivada em hidroponia. Santa Maria: UFSM, 1999. 79 p. (Dissertação mestrado).

SCHMIDT, D.; SANTOS, O.S. Cultivares de alface. In: SANTOS, O. Hidroponia da Alface. Santa Maria: UFSM, 2000. p. 72-79.

SCHMIDT, D.; SANTOS, O.S.; FAGAN, E.B.; LONDERO, F.A.A. Eficiência de soluções hidropônicas em cultivo de alface. Horticultura Brasileira, Brasília, v. 18, p. 269-271, 2000, suplemento. 